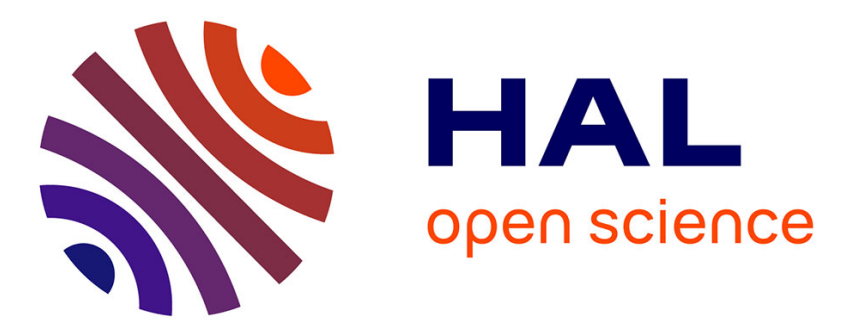

\title{
An energy analysis of parametric roll for application to the second generation intact stability criteria
}

François Grinnaert, Jean-Yves Billard, Jean-Marc Laurens

\section{To cite this version:}

François Grinnaert, Jean-Yves Billard, Jean-Marc Laurens. An energy analysis of parametric roll for application to the second generation intact stability criteria. Journal of Marine Science and Technology, 2017, 22 (3), pp.587-600. 10.1007/s00773-017-0444-z . hal-01699481

\section{HAL Id: hal-01699481}

\section{https://hal-ensta-bretagne.archives-ouvertes.fr/hal-01699481}

\author{
Submitted on 18 Oct 2021
}

HAL is a multi-disciplinary open access archive for the deposit and dissemination of scientific research documents, whether they are published or not. The documents may come from teaching and research institutions in France or abroad, or from public or private research centers.
L'archive ouverte pluridisciplinaire HAL, est destinée au dépôt et à la diffusion de documents scientifiques de niveau recherche, publiés ou non, émanant des établissements d'enseignement et de recherche français ou étrangers, des laboratoires publics ou privés. 


\title{
An energy analysis of parametric roll for application to the second generation intact stability criteria
}

\author{
François Grinnaert $^{1}$, Jean-Yves Billard ${ }^{2}$, Jean-Marc Laurens ${ }^{3}$
}

\begin{abstract}
Parametric roll is an amplification of the roll motion due to the periodic variation of the restoring moment in waves. This phenomenon is mostly observed in head and following seas and is the cause of several accidents occurred on container vessels during recent decades. One of the second generation intact stability criteria, currently under finalization and validation by the IMO, requires computing the maximum roll angle with regard to parametric roll. Both proposed methods are relatively complex to implement and require tools that naval architects are not accustomed to. In this paper, we propose an easier alternative method providing the amplitude of parametric roll for any loading condition at any speed, based on energy considerations and assuming a linear GZ. The implementation of this easy method in the corresponding second generation intact stability criterion provides almost the same value of $\mathrm{KG}_{\max }$ than the on-degree-of-freedom time simulation proposed by the future regulation.
\end{abstract}

Keywords Stability $\cdot$ Parametric roll $\cdot$ Energy $\cdot$ Second generation intact stability criteria

François Grinnaert

francois.grinnaert@ecole-navale.fr

Jean-Yves Billard

jean-yves.billard@ecole-navale.fr

Jean-Marc Laurens

Jean-Marc.LAURENS@ensta-bretagne.fr

1 French Naval Academy Research Institute, Brest, France

2 French Naval Academy Research Institute, Brest, France

3 ENSTA Bretagne, Brest, France

\section{Introduction}

Parametric roll is an amplification of the roll motion of ships due to the periodic variation of the restoring moment in waves. This phenomenon is mostly observed in head and following seas when the wave encounter frequency is nearly twice the ship's natural roll frequency and the roll damping is insufficient. Although parametric resonance has long been recognized by mathematicians [19], mechanics and optical engineers $[8,21]$ or even naval architects $[7$, 17], it has recently been highlighted with regard to the roll motion of container vessels $[5,6]$ with high financial and safety risks (extreme roll angle, container loss, capsizing).

The second generation intact stability criteria are currently being finalized and validated by the International Maritime Organization [14, 15]. This future regulation is structured in five failure modes, including parametric roll. Three levels of assessment are defined in each failure mode. The first assessment level criterion is set in order to require simple and approximate evaluations and hence entails a larger safety margin. The second assessment level is based on probabilistic approaches of the phenomena. It requires more complex computations based on hydrostatic considerations with regard to static sinusoidal waves. The safety margins are adjusted accordingly. The third assessment level, currently under development, should consist of a direct assessment using numerical six-degrees-of-freedom simulations performed by specialized institutes and presumably resulting in optimized safety margins.

The level-two criterion of the parametric roll failure mode consists of two checks. The second one, marked $\mathrm{C} 2$, requires the computation of the maximum roll angle for several speeds in head and following seas for any considered loading condition defined by both the draught and KG 
(vertical centre of gravity). The criterion considers that the maximum parametric roll angle cannot exceed $25^{\circ}$.

The new regulation proposes 2 methods: an analytical solution based on a polynomial fit of the GZ curve at the 5 th order which directly yields the maximum roll angle, or a numerical solving of the differential equation of parametric roll, equivalent to a one-degree-of-freedom simulation of the behaviour of the ship during rolling. Both methods are relatively complex to implement and require tools that naval architects are not accustomed to.

Parametric roll has been extensively studied through analytical, numerical and experimental approaches [2, 4, $11,20,22]$. In some papers, authors explain that the steadystate roll amplitude occurs if the energy provided by the variation over time of the restoring moment is entirely dissipated by roll damping [1,3]. However, to the best of our knowledge, no paper explores the energy problem in a quantitative manner, except the contribution of Kerwin [17]. In our paper, we propose to perform an energy analysis of parametric roll with the aim to provide a simplified method which yields the maximum roll amplitude assuming a linear GZ in the scope of an implementation in the level-two parametric roll future criteria. Since the threshold value of roll angle is specified to $25^{\circ}$, the linear-GZ assumption is relevant or conservative for most of the ships.

The first part of this study consists of an analytical approach of the energy transfer of parametric roll in the resonance condition, where the wave encounter frequency is twice the ship's natural roll frequency. Subsequently, the behaviour of the ship in other conditions with and without parametric roll is presented. Finally, a simplified method which provides the amplitude of steady-state parametric roll is proposed assuming a linear GZ.

\section{Parametric roll in resonance condition}

\subsection{Equation of parametric roll}

Parametric roll in pure head or following seas (i.e. with no transverse excitation) is represented in one degree of freedom by the following differential equation:

$J_{44} \ddot{\phi}+B_{44} \dot{\phi}+W G Z(\phi, t)=0$

with $J_{44}$ is roll moment of inertia, including added mass $\left(\mathrm{kg} \mathrm{m}^{2}\right) ; B_{44}$ is the damping coefficient ( $\left.\mathrm{N} \mathrm{m} \mathrm{s} / \mathrm{rad}\right)$; $\mathrm{W}$ is the ship's weight $(\mathrm{N})$; GZ $(\phi, \mathrm{t})$ is the righting arm, function of both the instantaneous roll angle $\phi$ and time $t$ with the wave encounter frequency $(\mathrm{m})$.

We assume a linear GZ in this paper. Hence, the differential equation is rewritten:

$J_{44} \ddot{\phi}+B_{44} \dot{\phi}+W\left(G M+\Delta G M \cos \omega_{e} t\right) \phi=0$ with GM is average value of the metacentric height in waves (m); $\Delta \mathrm{GM}$ is half-amplitude of the metacentric height variation in waves $(\mathrm{m}) ; \omega_{e}$ is wave encounter frequency $(\mathrm{rad} / \mathrm{s})$.

Equation 2 is a linear differential equation with non-constant terms. The added mass in the first term depends on the roll frequency. The second term $\left(B_{44}\right)$ depends on the roll amplitude and frequency, especially if Ikeda method is used [16]. The third term varies over time with the wave encounter frequency. We reformulate Eq. 2 by moving the non-constant part of the restoring moment to the right as follows:

$J_{44} \ddot{\phi}+B_{44} \dot{\phi}+W G M \phi=-\left(W \Delta G M \cos \omega_{e} t\right) \phi$.

The left-hand part of Eq. 3 is identical to the one of the well-known differential equation of a linear oscillating system. Although it is not properly correct because of the dependency on $\phi$, the right-hand part is considered as an exciting moment in this paper. The energy provided by this moment is named "applied energy" by Kerwin [17]. In this paper, we name it "exciting energy".

\subsection{Assumptions}

The first assumption, previously introduced, is the linearity of GZ. It is used throughout the paper.

Other following assumptions are formulated in this section:

The analysis is performed when the roll motion has reached a steady-state amplitude (denoted by $\Phi$ ), i.e. when the transient movement has finished;

The ship rolls at its natural frequency $\omega_{0}$ are defined as

$\omega_{0}=\sqrt{\frac{W G M}{J_{44}}}$.

The wave encounter frequency $\omega_{e}$ is twice the ship's natural roll frequency $\omega_{0}$. This corresponds to the resonance condition of the first mode of parametric roll.

Assumptions on both the roll amplitude and frequency render the first and second terms (respectively $J_{44}$ and $B_{44}$ ) constant in the differential equation. These assumptions provide expressions for the function of the roll angle over time and its first derivate:

$\phi(t)=\Phi \cos \omega_{0} t \quad \dot{\phi}(t)=-\omega_{0} \Phi \sin \omega_{0} t$.

\subsection{Distribution of energy}

\subsubsection{Kinetic energy and potential energy}

Assuming the ship rolls at its natural frequency, the sum of kinetic energy $\left(E_{\mathrm{K}}\right)$ and potential energy $\left(E_{\mathrm{P}}\right)$ contained, respectively, in the first term (inertia) and third term 
(constant part of restoring moment) of Eq. 3 is constant and equal to

$E_{K}+E_{P}=\frac{1}{2} W G M \Phi^{2}$

Consequently, the assumption of a constant roll amplitude $\Phi$ causes the energy provided by the exciting moment $\left(E_{\mathrm{E}}\right)$ to entirely dissipate by the damping moment as a "damping energy" $\left(E_{\mathrm{D}}\right)$.

\subsubsection{Damping energy}

The damping energy during one roll period is formulated as follows:

$E_{D}=\int_{1 \text { per }} B_{44} \dot{\phi} d \phi$ With $d \phi=\dot{\phi} d t$.

Using Eq. 5, the energy dissipated by the damping moment from 0 to a time $t$ is

$E_{D}=B_{44} \omega_{0}^{2} \Phi^{2} \int_{0}^{t} \sin ^{2} \omega_{0} t d t$

The instantaneous power dissipated by damping is

$P_{D}(t)=\frac{d E_{D}}{d t}=B_{44} \omega_{0}^{2} \Phi^{2} \sin ^{2} \omega_{0} t$.

The average value of this power is

$P_{D}=\frac{1}{2} B_{44} \omega_{0}^{2} \Phi^{2}$

\subsubsection{Exciting energy}

The exciting energy during one roll period is formulated as follows:

$E_{E}=-W \Delta G M \int_{1 \text { per }} \phi \cos \left(\omega_{e} t+\alpha\right) d \phi$.

The angle $\alpha$ is required here because the variation of GM in waves may not be in phase with the roll motion. In this paper, this angle is called the "shift angle". Using the expression of $\phi$ and $\mathrm{d} \phi / \mathrm{dt}$ in Eq. 5 and the expression of $\mathrm{d} \phi$ in Eq. 7, we construct the following expression of the exciting energy between 0 and a time t:

$E_{E}(t)=W \Delta G M \omega_{0} \Phi^{2} \int_{0}^{t} \cos \omega_{0} t \sin \omega_{0} t \cos \left(\omega_{e} t+\alpha\right) d t$.

The instantaneous exciting power is
$P_{E}(t)=\frac{d E_{E}}{d t}=W \Delta G M \omega_{0} \Phi^{2} \cos \omega_{0} t \sin \omega_{0} t \cos \left(\omega_{e} t+\alpha\right)$.

The assumption regarding the wave encounter frequency $\left(\omega_{e}=2 \omega_{0}\right)$ and trigonometric identities allows a simplification of this equation:

$P_{E}(t)=\frac{1}{4} W \Delta G M \omega_{0} \Phi^{2}\left[\sin \left(4 \omega_{0} t+\alpha\right)-\sin \alpha\right]$

Consequently, the average value of the exciting power is a function of the shift angle $\alpha$ :

$P_{E}=-\frac{1}{4} W \Delta G M \omega_{0} \Phi^{2} \sin \alpha$.

The maximum value of the exciting power is obtained for $\alpha=-\pi / 2$ :

$P_{E . \max }=\frac{1}{4} W \Delta G M \omega_{0} \Phi^{2}$

\subsection{Direct calculation of the maximum roll angle in resonance condition}

\subsubsection{Required damping coefficient}

Assuming the steady state of parametric roll amplitude and the worst case of shift angle $(\alpha=-\pi / 2)$, the exciting energy is entirely dissipated if the damping coefficient can attain a required value $B_{44 \text {.req }}$ defined by the equality between $P_{\mathrm{D}}$ (Eq. 10) and $P_{\text {E.max }}$ (Eq. 16):

$B_{44 . r e q}=\frac{W \Delta G M}{2 \omega_{0}}$.

The roll amplitude $\Phi$ does not appear directly in this relationship. If the damping coefficient $B_{44}$ is independent from the roll amplitude (i.e. linear damping), parametric roll cannot appear when its value is larger than the required

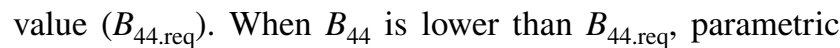
roll appears with very large roll amplitude or causes the vessel to capsize, subject to the linear-GZ assumption.

However, the damping coefficient is a function of the roll amplitude as proposed by Ikeda method [16]. Consequently, this approach provides an easy direct calculation of the maximum parametric roll amplitude $\Phi_{\max }$ (corresponding to both the resonance condition and the worst case of shift angle) by solving the following equation:

$B_{44}\left(\Phi_{\max }\right)=\frac{W \Delta G M}{2 \omega_{0}}$.

In 1955, Kerwin [17] arrived at the same conclusion using both analytical solving of the differential equation and energy consideration, assuming a non-linear damping. In the second method, the exciting energy is 
provided by a vertical movement of the centre of gravity, causing an equivalent variation of GM while the metacentre is motionless.

\subsubsection{Comparison with time-domain simulation}

The method described above is used to calculate the maximum roll angle in resonance condition for the $\mathrm{C} 11$ container vessel presented by France, et al. [6] at a draught equal to $12 \mathrm{~m}$. As required by the first-level criterion of the future regulation [14], hydrostatics are computed in waves which have a length equal to the length between perpendiculars $(262 \mathrm{~m})$ and a wave steepness equal to 0.0167 . This causes the wave height to be equal to $4.375 \mathrm{~m}$ and the half-amplitude of the GM variation $(\Delta \mathrm{GM})$ equal to $1.511 \mathrm{~m}$, independent of KG. The damping coefficients $B_{44}$ are calculated according to Kawahara, Maekawa \& Ikeda [16] and Ikeda, Himeno \& Tanaka [12] for the lift component. The results are provided in Table 1 and Fig. 1. For each value of $\mathrm{KG}$, the speed is calculated for the parametric resonance condition. Positive speeds correspond to the head seas and negative speeds correspond to the following seas. The resulting maximum roll angle $\left(\Phi_{\max }\right.$ in Table 1$)$ is compared to the value obtained by the numerical solving of the differential equation (Eq. 2) using the method of Runge-Kutta at the 4th order and a simulation duration equal to 20 times the ship's natural roll period $\left(\Phi_{\max } \operatorname{sim}\right.$ in Table 1). We observe that both values of the maximum roll angle are almost equal (both calculations are limited to $50^{\circ}$ ). In each case, the value obtained by the time-domain simulation is slightly lower than that obtained by the energy approach. This suggests that the duration of 20 natural roll
Table 1 Maximum roll angle in parametric resonance condition for the $\mathrm{C} 11$ container vessel

\begin{tabular}{lllrlll}
\hline KG $(\mathrm{m})$ & $\begin{array}{l}\text { Average } \mathrm{GM} \text { in } \\
\text { waves }(\mathrm{m})\end{array}$ & $\omega_{0}(\mathrm{rad} / \mathrm{s})$ & $\mathrm{V}(\mathrm{m} / \mathrm{s})$ & $B_{44 . \mathrm{req}}(\mathrm{N} \mathrm{m} \mathrm{s} / \mathrm{rad})$ & $\Phi_{\max }\left({ }^{\circ}\right)$ & $\Phi_{\max } \operatorname{sim}\left(^{\circ}\right)$ \\
\hline 15.0 & 5.445 & 0.406 & 13.64 & $1.34 \mathrm{E}+09$ & 17.96 & 17.83 \\
15.5 & 4.945 & 0.387 & 12.05 & $1.40 \mathrm{E}+09$ & 19.92 & 19.84 \\
16.0 & 4.445 & 0.367 & 10.37 & $1.48 \mathrm{E}+09$ & 22.26 & 22.20 \\
16.5 & 3.945 & 0.346 & 8.60 & $1.57 \mathrm{E}+09$ & 25.33 & 25.26 \\
17.0 & 3.445 & 0.323 & 6.71 & $1.68 \mathrm{E}+09$ & 29.75 & 29.66 \\
17.5 & 2.945 & 0.299 & 4.68 & $1.82 \mathrm{E}+09$ & 38.08 & 37.85 \\
18.0 & 2.445 & 0.272 & 2.47 & $2.00 \mathrm{E}+09$ & 50 & 50 \\
18.5 & 1.945 & 0.243 & 0.01 & $2.24 \mathrm{E}+09$ & 50 & 50 \\
19.0 & 1.445 & 0.209 & -2.78 & $2.60 \mathrm{E}+09$ & 50 & 50 \\
19.5 & 0.945 & 0.169 & -6.12 & $3.21 \mathrm{E}+09$ & 50 & 50 \\
20.0 & 0.445 & 0.116 & -10.55 & $4.68 \mathrm{E}+09$ & 50 & 50 \\
\hline
\end{tabular}

Fig. 1 Maximum roll angle in parametric resonance condition for the $\mathrm{C} 11$ container vessel (both curves coincide)

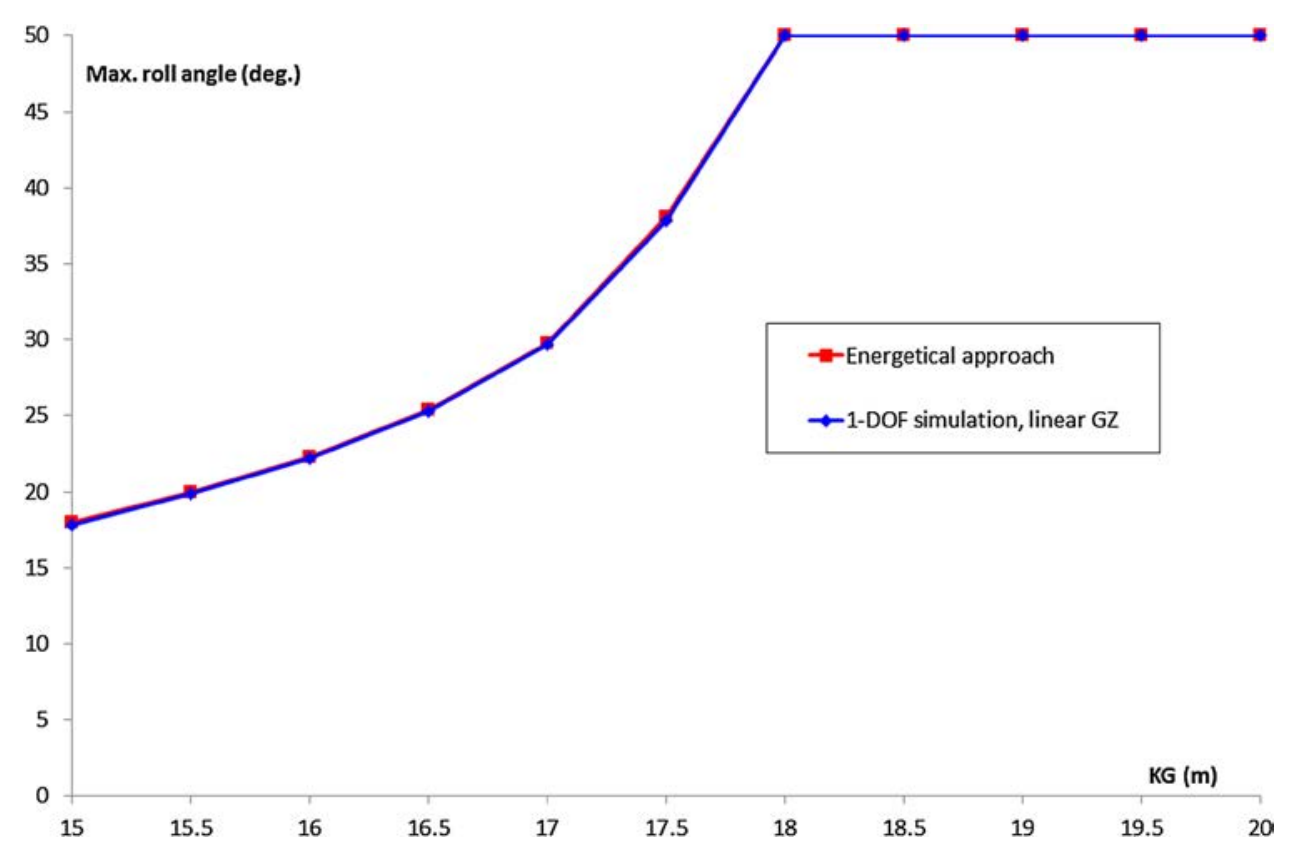


periods of the ship is not long enough to attain the steadystate roll amplitude.

Moreover, the direct calculation of the maximum roll angle is performed assuming the worst case of shift angle $(\alpha=-\pi / 2)$. Equality between the values of the maximum roll angle calculated with both methods seems to show that this assumption is correct. Figure 2 shows the variation of roll angle over time during the numerical solving of the differential equation. This time-domain simulation in one degree of freedom starts with an initial angle equal to $10^{\circ}$ and a shift angle $\alpha$ equal to zero, which reduces the exciting power to zero. During the first period, we observe a slight decrease of the roll amplitude (the roll angle is $8.9^{\circ}$ at the end of the period). After that, the amplitude increases up to the steady state. The frequency of the roll motion during the first period is $0.396 \mathrm{rad} / \mathrm{s}$. Its value during the steady state is $0.369 \mathrm{rad} / \mathrm{s}$. This shows that the roll motion automatically shifts in waves at the start of the simulation in order to attain the shift angle which provides maximum exciting energy $(-\pi / 2)$. The assumption of the worst case of shift angle in parametric resonance condition is verified.

\section{Parametric roll in other conditions}

In this section and the next one, the roll frequency is denoted by $\omega$ and may differ from the natural roll frequency $\omega_{0}$. The encounter frequency $\omega_{e}$ may be non-synchronized with $\omega$. We introduce $\gamma_{0}$ and $\gamma$ as follows:

$\gamma_{0}=\frac{\omega_{e}}{\omega_{0}}$ And $\gamma=\frac{\omega_{e}}{\omega}$.

\subsection{Non-synchronized parametric roll}

If the roll frequency $\omega$ differs from the natural frequency $\omega_{0}$, the sum of the kinetic and potential energies is not constant in time. However, their sum is a sinusoidal function. Its average value, equivalent to the average power required to maintain the roll motion, is zero. Consequently, like for the synchronized parametric roll, the assumption of constant roll amplitude causes the energy provided by the exciting moment to entirely dissipate by the damping moment.

Modifying Eq. 13 for the general case yields the following relationship for the exciting power:

$P_{E}(t)=W \Delta G M \omega_{0} \Phi^{2} \cos \omega t \sin \omega t \cos \left(\omega_{e} t+\alpha\right)$.

Trigonometric identities allow a modification of this relationship as follows:

$P_{E}(t)=\frac{1}{4} W \Delta G M \omega_{0} \Phi^{2}[\sin ((2-\gamma) \omega t-\alpha)+\sin ((2+\gamma) \omega t+\alpha)]$

We observe that the average value of the exciting power is zero except if $\gamma$ is equal to 2 or -2 . The case $\gamma=-2$ corresponds to a non-realistically high speed in following seas. When the value of $\mathrm{KG}$ of the $\mathrm{C} 11$ container vessel is in the usual range from 15 to $20 \mathrm{~m}$, the corresponding resonance speed is in the range from $54 \mathrm{~m} / \mathrm{s}(\mathrm{KG}=15 \mathrm{~m})$ to $30 \mathrm{~m} / \mathrm{s}$ $(\mathrm{KG}=20 \mathrm{~m})$. This case is not considered in this paper.

If $\gamma$ is not equal to 2 but close to this value, the exciting power consists of two frequencies: a high frequency equal to $(2+\gamma) \omega$ and a low one equal to $(2-\gamma) \omega$. Figure 3 shows the roll angle plotted as a function of time resulting
Fig. 2 Roll angle versus time in parametric resonance condition

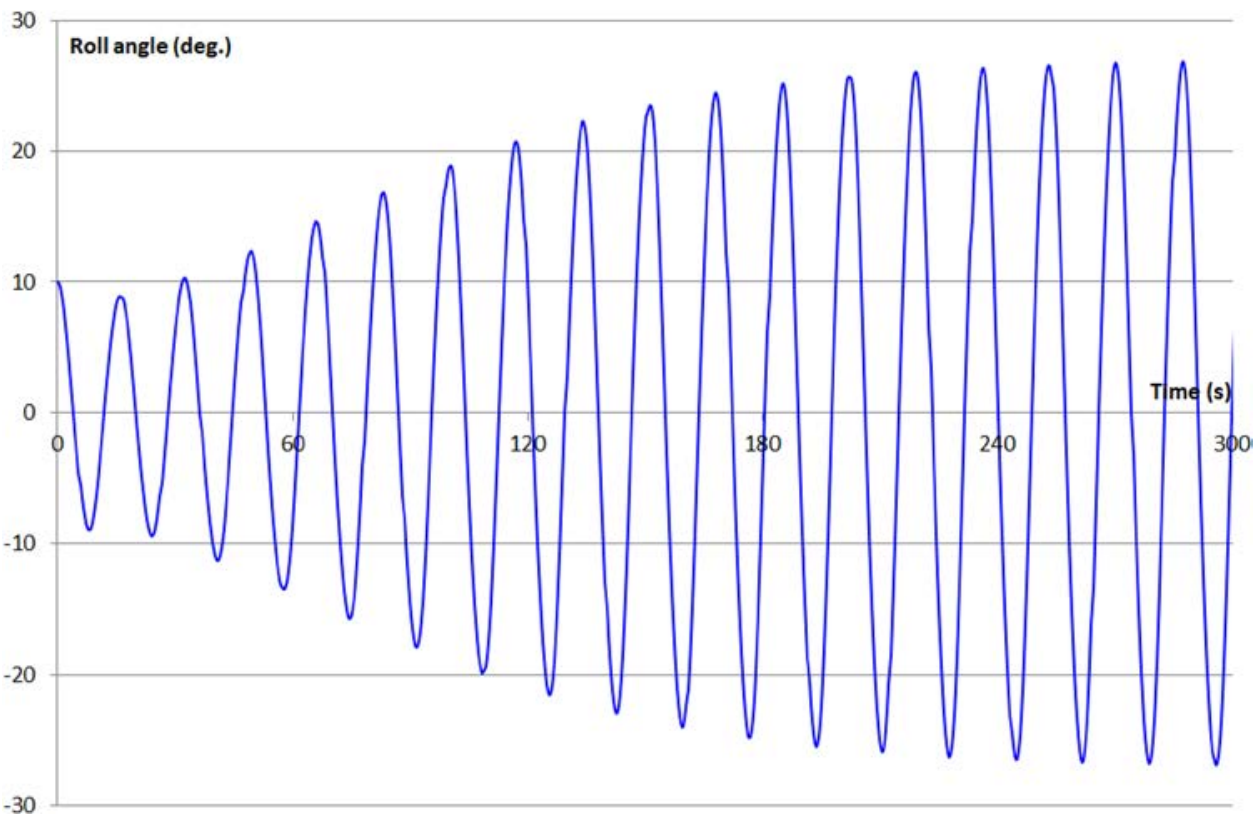


Fig. 3 Roll angle versus time in non-synchronized parametric roll condition

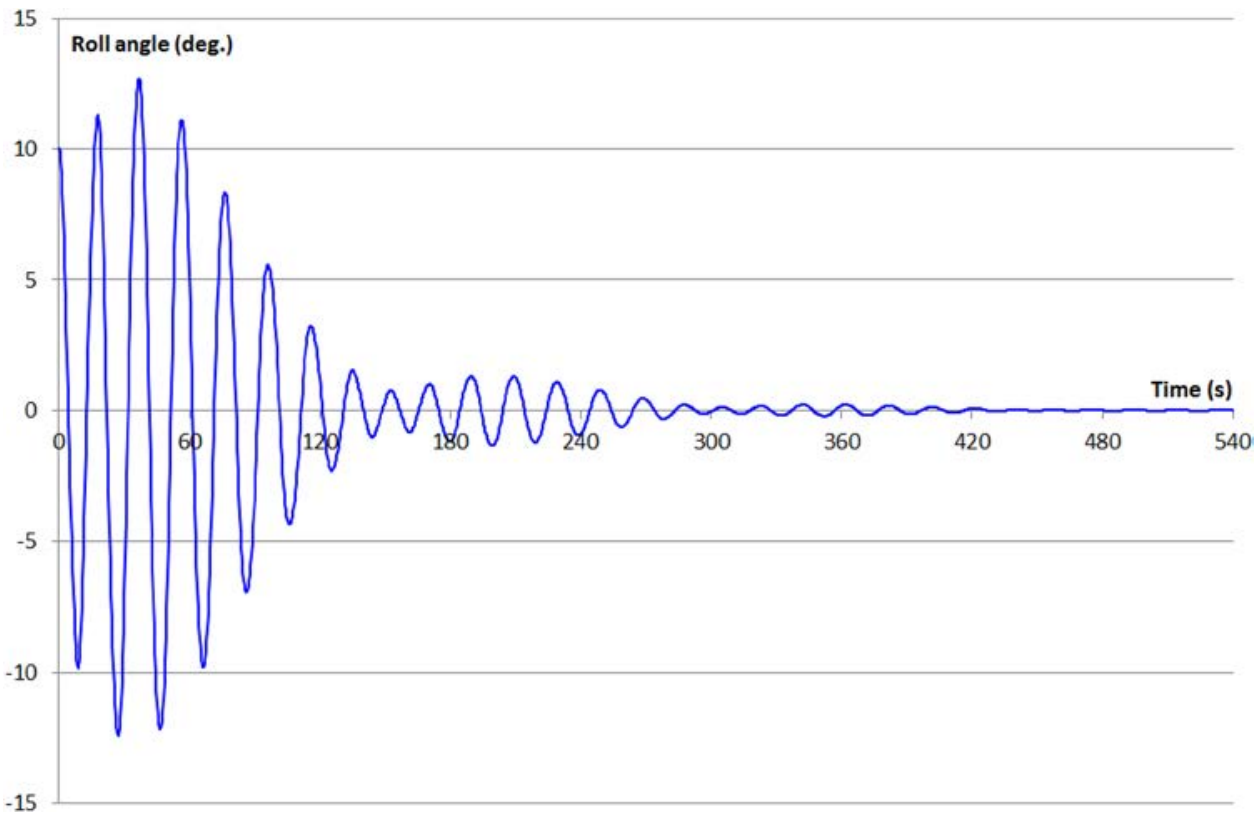

from a time-domain simulation in this condition. The speed of parametric resonance is equal to $8.8 \mathrm{~m} / \mathrm{s}$ and the ship's speed equal to $5.5 \mathrm{~m} / \mathrm{s}$. We observe long periods which could be seen as corresponding to the low frequency part of the exciting power. In these long periods, parametric roll successively appears and disappears passing through a maximum. The roll frequency $\omega$ during the two first long periods of this simulation (0-150 s and 150-300 s) remains almost unchanged (respectively, 0.315 and $0.316 \mathrm{rad} / \mathrm{s}$ ) but roll motions are not in phase. This shows again that the roll motion automatically shifts in waves in order to capture the maximum exciting energy. The encounter frequency is equal to $0.617 \mathrm{rad} / \mathrm{s}$, which renders $\gamma$ equal to 1.95 during both first long periods of parametric roll. However, it is not possible to exactly find the low frequency of the exciting power $((2-\gamma) \omega)$ in Fig. 3 because of the shift of the roll motion.

Nevertheless, the roll amplitude rapidly tends to zero in this non-synchronized condition. Although parametric roll periodically exists during a short time, it may be ignored because the risk for the vessel is zero.

\subsection{Lock-in field}

We now propose to examine the behaviour of parametric roll close to the resonance condition by performing numerical one-degree-of-freedom simulations for all possible speeds in head seas (positive speed) and following seas (negative speed) and to look at both the maximum roll angle and the ship's roll period (called "observed roll period", calculated at zero-crossing in the second half-time of the simulation). Results for the C11 container vessel with draught, KG and mean GM in waves, respectively, equal to 12, 17.5 and 2.95 metres and are shown in Fig. 4. The vertical dashed line indicates the speed corresponding to the resonance condition. The horizontal dashed line indicates the natural roll period. The dashed hyperbole represents twice the encounter period and the black dot represents the maximum roll amplitude provided by the direct energy calculation. We observe the following facts:

1)The maximum roll angle occurs at a slightly lower speed than that of the resonance condition and is slightly higher than the speed calculated by the energy approach. We could believe that this is due to the reduction of roll damping at lower speed but similar calculations performed with a roll damping coefficient independent of the speed yield similar results. This fact remains unexplained at this time.

2)Parametric roll exists at a range of speeds from 1.5 to $7.7 \mathrm{~m} / \mathrm{s}$, in which the observed roll period is locked at twice the encounter period (i.e. $\gamma_{0}=2$ ). We call this range "lock-in field".

3)Outside this range, parametric roll does not occur (the maximum roll angle is roughly equal to the initial value used in the numerical solving, $1^{\circ}$ ) or is limited to the non-synchronized configuration previously presented. The observed roll period seems erratic; its calculation is disturbed by the shift of the roll motion. It tends to be close to the natural roll period.

4)As expected, the observed roll period in resonance condition is equal to the natural roll period and the maximum roll angle is equal to the one calculated by the energy approach. 
Fig. 4 Maximum roll angle and roll period versus speed

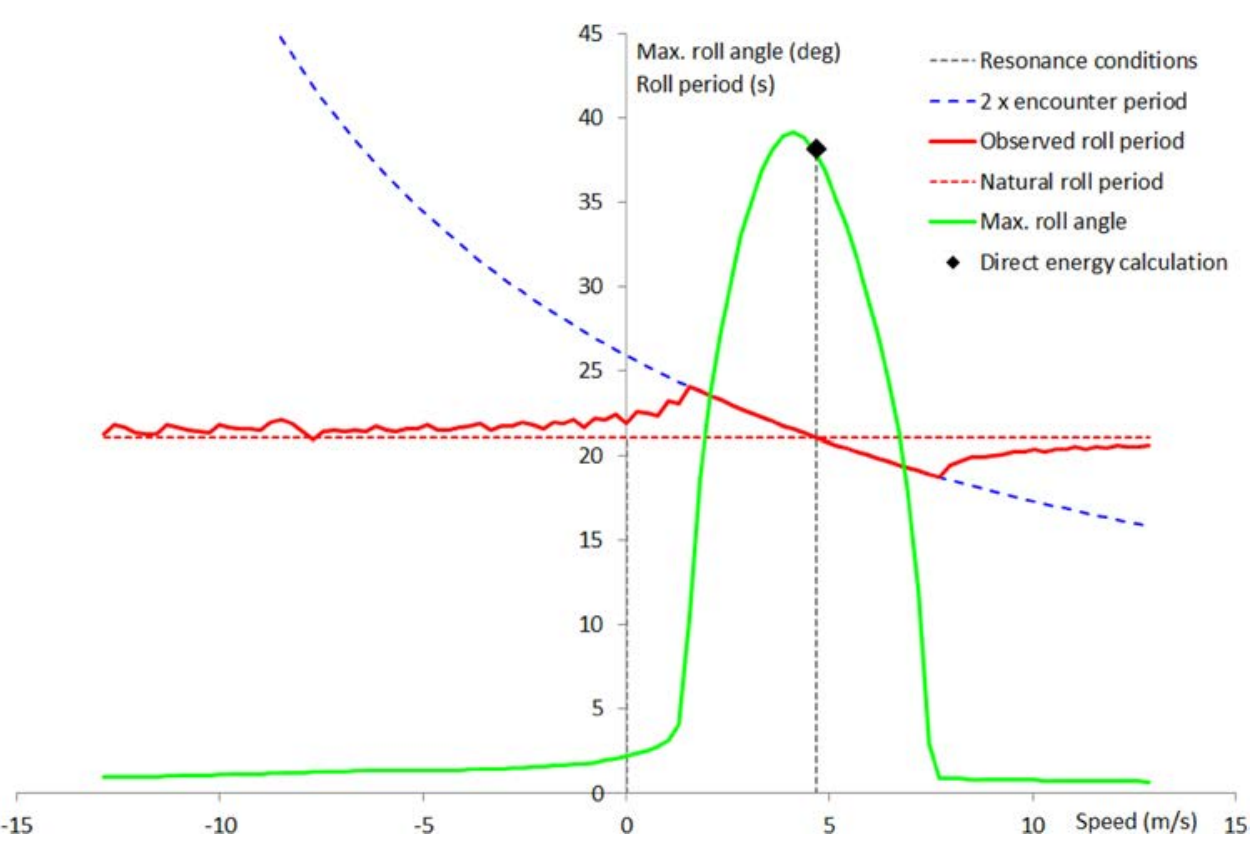

\subsection{Second and third modes of parametric roll}

Figure 5 shows a similar calculation performed with a KG increased to $18.45 \mathrm{~m}$ and a mean GM in waves reduced to $2.00 \mathrm{~m}$. The maximum roll angle in the lock-in field is larger than $50^{\circ}$ and the ship would possibly capsize in the vicinity of the resonance condition. We observe a second lock-in field corresponding to the second mode of parametric roll, characterized by equality between both the roll frequency and the encounter frequency $\left(\gamma_{0}=1\right)$. This lock-in field is not exactly centred on the second resonance speed
$(9.98 \mathrm{~m} / \mathrm{s}$, following seas) but passes through this value. The maximum roll angle occurs at a speed lower than the resonance speed, possibly for the same unexplained reasons than what is observed in the first mode of parametric roll. The value of the maximum roll angle is $2.2^{\circ}$, negligible compared to what occurs in the first mode. The width of the second lock-in field is also reduced.

The third mode of parametric roll $\left(\gamma_{0}=2 / 3\right)$ is neither observable in the roll period nor in the roll amplitude for this vessel. In the conditions of Fig. 5, the corresponding speed is $13.4 \mathrm{~m} / \mathrm{s}$ in following seas. However, it can be
Fig. 5 Maximum roll angle and roll period versus speed with lower GM

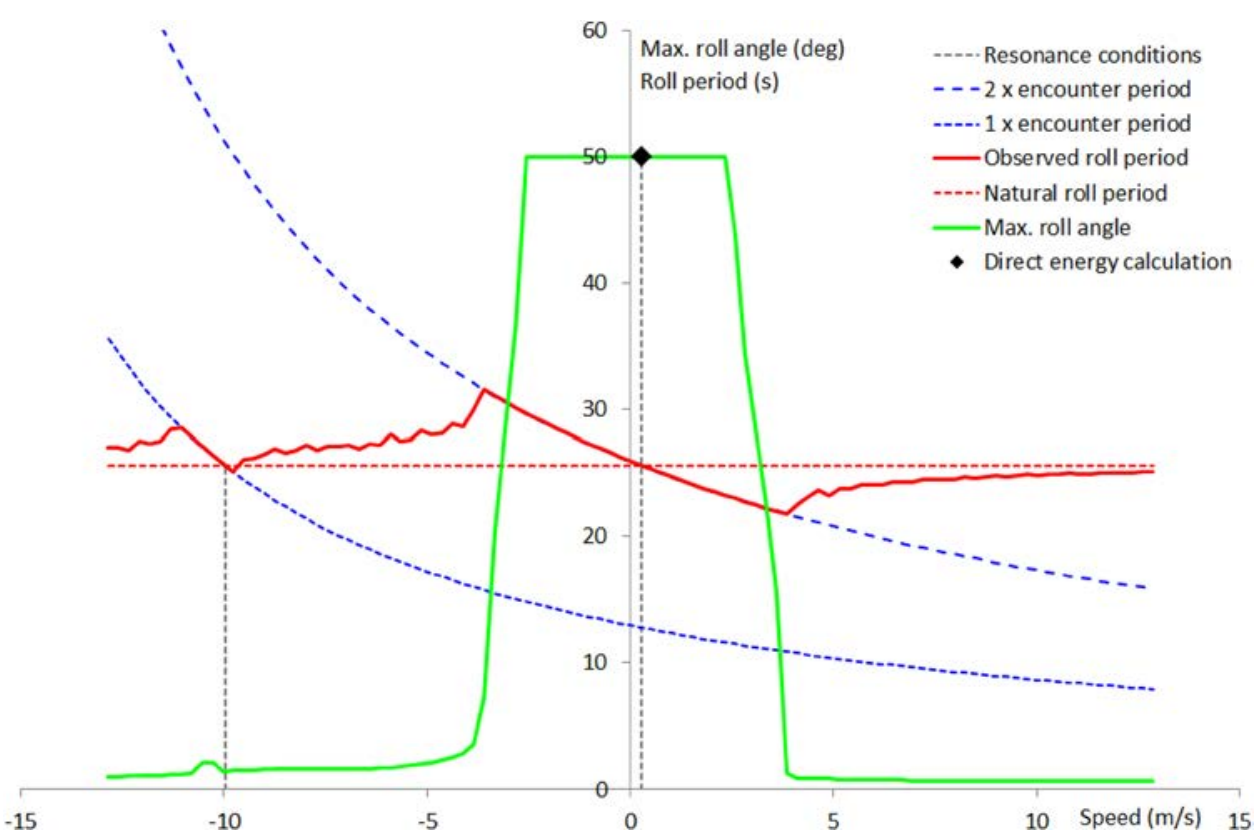


observed in non-realistic conditions as shown in Fig. 6, where the speed range has been enlarged, the GM variation has been increased (i.e. the wave steepness does not correspond to the future regulation requirement any longer) and the damping coefficient has been customized. We observe that the third lock-in field is narrow and the corresponding maximum roll angle is negligible.

\subsection{Shift angle in the lock-in field}

The shift angle $\alpha$ can be calculated by comparing the resulting variation of the roll angle and the variation of the metacentric height imposed during the time-domain simulation. Figure 7 shows the evolution of its absolute value as a function of $\gamma_{0}$. All data are dimensionless in this figure: the maximum roll angle is divided by the value obtained with the direct energy calculation; the periods are divided by the ship's natural roll period and the shift angle is divided by $-\pi / 2$. We observe that its
Fig. 6 Three modes of parametric roll
Fig. 7 Evolution of the shift angle in the lock-in field
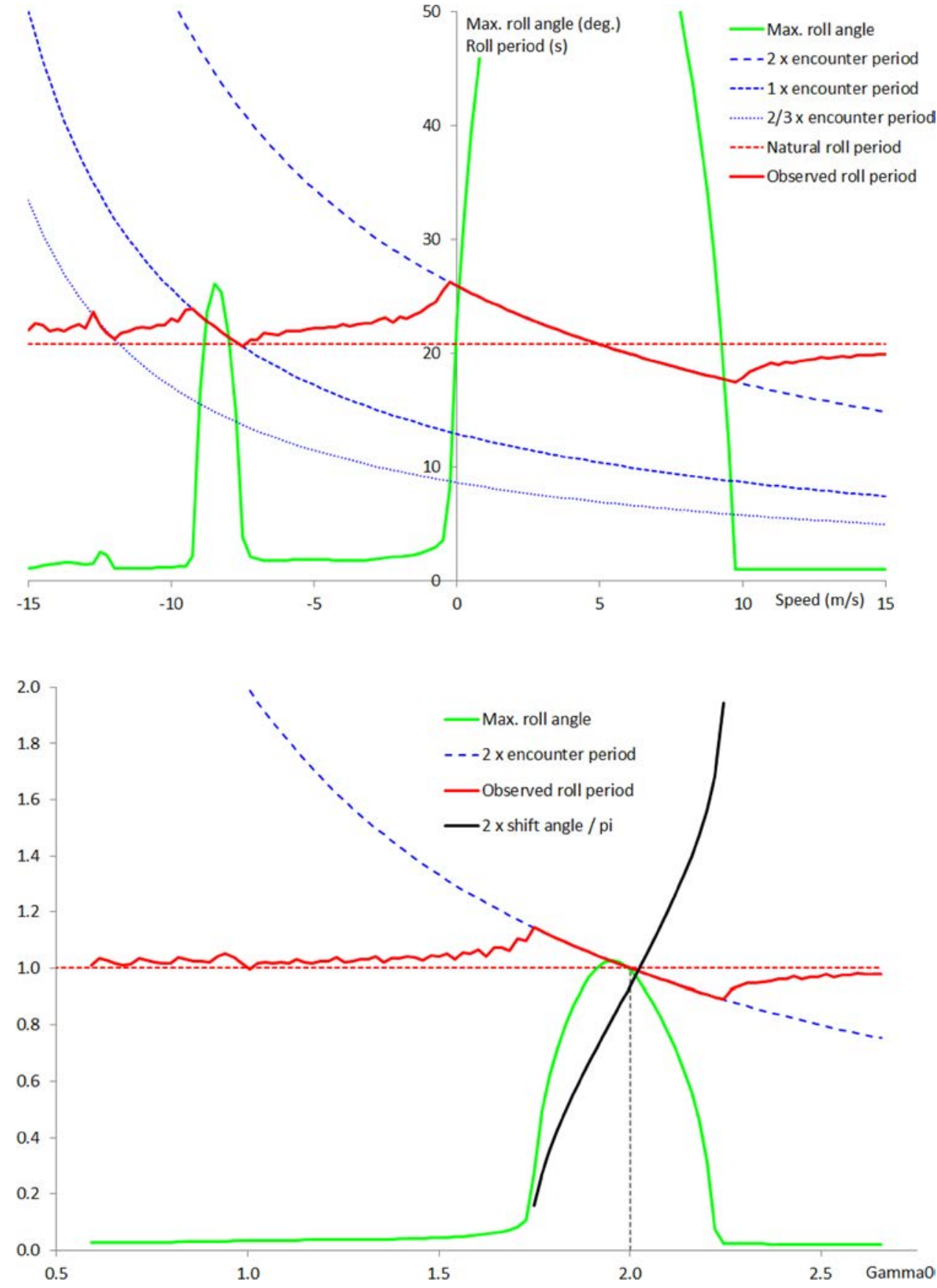
value starts from near zero at the left (low-speed side of the lock-in field), is equal to $-\pi / 2$ near the resonance condition $\left(\gamma_{0}=2\right)$ and continues up to approximately $-\pi$ at the right end of the lock-in field (high-speed side). Since the exciting power is reduced by $\sin (\alpha)$, this evolution is in accordance with the evolution of the maximum roll angle observed in the lock-in field. The shift angle is not drawn outside the lock-in field since it has no significance here.

\subsection{Width of the lock-in field}

The width of the lock-in field is the difference of $\gamma_{0}$ at both ends of the field. Its value is almost equal to $\Delta \mathrm{GM} / \mathrm{GM}$. In 1955, Kerwin [17] demonstrated an equivalent result both without and with damping from an approximate solution of Eq. 2. This observation has been made for all calculations performed on the $\mathrm{C} 11$ container vessel, for any values of the average metacentric height in waves and its variation (respectively, GM and $\Delta \mathrm{GM}$ ). This observation has also been made for the three other vessels examined within the scope of this paper: another container vessel (319 m long), a roll-on roll-off vessel $(135 \mathrm{~m})$ and a tanker $(227 \mathrm{~m})$. The second generation intact stability criteria of level one and level two assess these vessels as, respectively, vulnerable (similar to the $\mathrm{C} 11$ container vessel), slightly vulnerable and non-vulnerable to parametric roll [9].

Moreover, it seems interesting to validate the location and the width of the lock-in field with a computation of higher accuracy than that of the one-degree-of-freedom simulation with a linear GZ. Fredyn software is used for this [18]. This software has been developed by the members of Cooperative Research Navies (CRNAV, http://www. crnav.org) and performs 6 degrees-of-freedom simulations of steered ships in extreme seas and wind. It is used within the scope of this paper to simulate the behaviour of the C11 container vessel in one loading condition (draught $12 \mathrm{~m}$, $\mathrm{KG} 18 \mathrm{~m}$ ) in sinusoidal waves which have the required characteristics (length $262 \mathrm{~m}$, steepness 0.0167), in head sea and following sea conditions. Figure 8 shows the maximum roll angle provided by both 1 - and 6-degrees-of-freedom simulations. We observe the following facts:

1)Both fields of parametric roll coincide perfectly. The location and the width of the lock-in field obtained with 1-DoF simulations are validated.

2)The maximum roll amplitude provided by 6-DoF simulations is significantly smaller than the amplitude obtained by $1-$ DoF simulations. This is due to the dispersion of energy in the 5 other degrees of freedom and to non-linear effects. Moreover, the methods used for roll damping are not the same in 1-DoF and 6-DoF simulations.

3)Keeping the ship's heading is impossible at zero speed in waves. This causes the trough observed at this speed in the 6-DoF curve.

4)The second mode of parametric roll is clearly visible in 6-DoF simulations but its peak does not occur exactly at the expected speed.
Fig. 8 Maximum roll angle versus speed provided by $1-\mathrm{DoF}$ and 6-DoF simulations

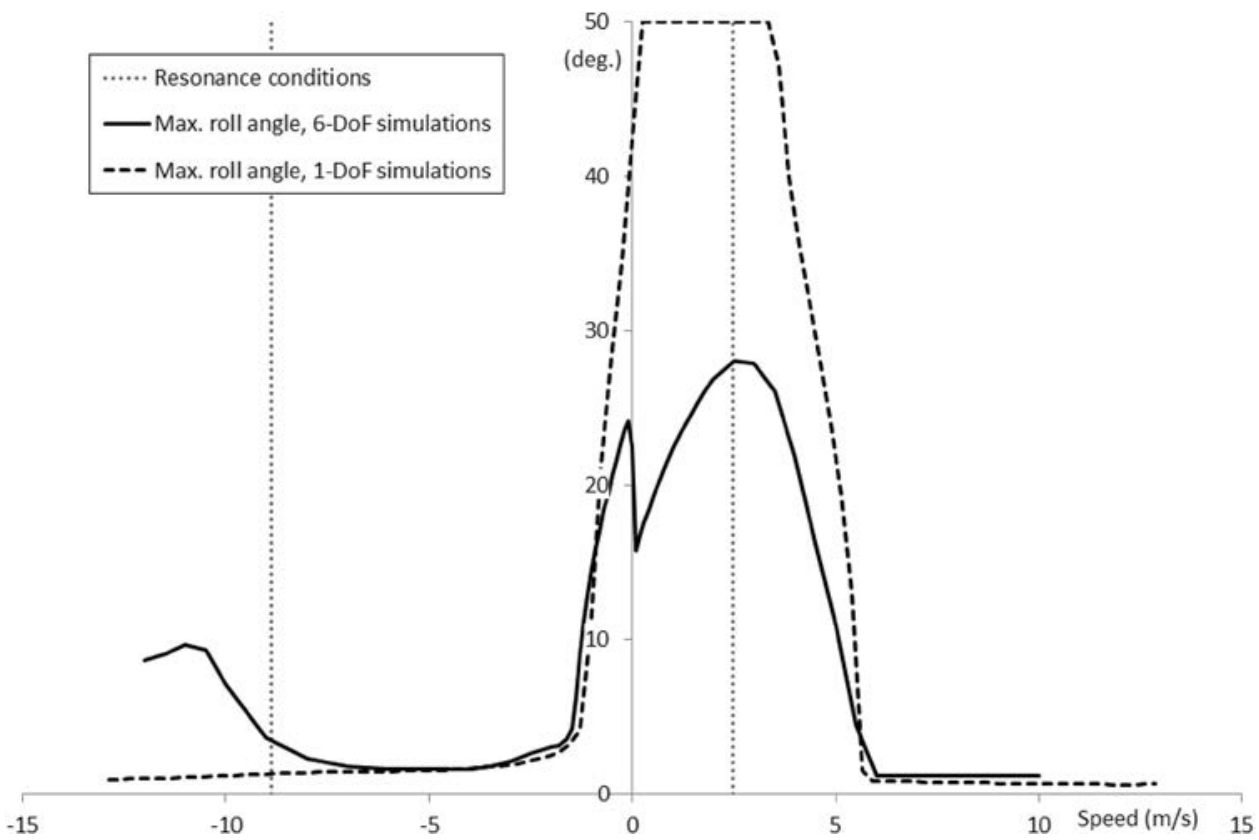




\section{Method providing steady-state parametric roll amplitude at any speed}

We are able to easily calculate the maximum parametric roll amplitude which occurs in the first-mode resonance condition assuming a linear GZ. Moreover, we can predict the width of the lock-in field, in which parametric roll exists, and the evolution of the shift angle in this field. We assume a linear evolution from 0 to $-\pi$. These points allow the establishment of a simplified method providing the parametric roll amplitude in all speed conditions.

\subsection{Energy method}

We propose a practical method, called "energy method", which provides the parametric roll amplitude in all speed conditions for a specific loading condition (draught and KG). Only the first mode is considered. This method consists of two steps.

\subsubsection{First step}

The first step consists of computing the parametric roll amplitude at the speed corresponding to the resonance condition. This speed is obtained by the following relationship:

$V_{1 s t \bmod e}=\left(2 \omega_{0}-\omega_{w}\right) \frac{g}{\omega_{w}^{2}}$,

where $\omega_{w}$ is the wave frequency ( $\left.\mathrm{rad} / \mathrm{s}\right)$ and $\mathrm{g}$ is the acceleration of gravity $\left(\mathrm{m} / \mathrm{s}^{2}\right)$.

The parametric roll amplitude at this speed, denoted by $\Phi_{\text {max }}$, is obtained by solving Eq. 18 , which can be easily done numerically on a spreadsheet.

The more difficult problems of this first step are as follows:

- The handling of the Ikeda method: although the number of coefficients to be calculated is large, there is neither hard relationship nor integral to deal with.

- The computation of the GM variation in sinusoidal waves, which requires an adequate hydrostatic tool: several hydrostatic software packages, currently used by naval architects, can be used to perform such computations.

\subsubsection{Second step}

For any speed V (m/s), we calculate $\gamma_{0}$ as follows:

$\gamma_{0}=\frac{\omega_{e}}{\omega_{0}}=\frac{\omega_{w}}{\omega_{0}}\left(1+\frac{V \omega_{w}}{g}\right)$.

The parametric roll amplitude is zero outside the lock-in field (the second and third modes are not considered) and non-zero inside. The lock-in field is defined by $\gamma_{0}$ in the range:
From $2-\frac{\Delta G M}{2 G M}$ To $2+\frac{\Delta G M}{2 G M}$

Assuming a linear evolution of the shift angle $\alpha$ in the lock-in field and a parametric roll amplitude proportional to $\sin (\alpha)$, this amplitude, denoted by $\Phi$, is obtained by

$\Phi=\Phi_{\max } \cos \left(\pi\left(2-\gamma_{0}\right) \frac{G M}{\Delta G M}\right)$.

\subsection{Improvement of the energy method}

The evolution of the shift angle in the lock-in field is not exactly linear, as shown in Fig. 7. The comparison of the roll amplitudes provided by the above method and those obtained with the 1-DoF simulation demonstrates that our method under-estimates the amplitude. Consequently, we propose to introduce an exponent $\mathrm{k}$ in Eq. 25 as follows:

$\Phi=\Phi_{\max } \cos ^{k}\left(\pi\left(2-\gamma_{0}\right) \frac{G M}{\Delta G M}\right)$.

Figure 9 shows the results provided by the proposed method with different values of the exponent for the C11 container vessel with the same loading condition as that in Fig. 4. Setting $\mathrm{k}$ to zero renders the roll amplitude equal to the value obtained in the resonance condition inside the entire lock-in field and zero outside the field. We propose $\mathrm{k}=1 / 2$ (plain line in Fig. 9). This value provides a good accuracy and a slight safety margin.

\subsection{Application to second generation intact stability criteria}

As mentioned above, the second check of the level- 2 criterion of the parametric roll failure mode requires computing the maximum roll angle for several wave cases and 7 speeds in head and following seas (independent from the resonance speed) for each wave and any considered loading condition. This criterion has been defined by the IMO in 2015 [14] and is enhanced by "Explanatory Notes" written in 2016 [15] providing explanations, comments and guidelines, such as the criteria of other failure modes because of their unusual complexity with regard to the current intact stability regulation [13].

We propose to implement the energy method in the computation of the second check of level-2 criterion of parametric roll. Computations are performed on the four vessels mentioned above and presented by Grinnaert, Billard and Laurens [9]: the C11 container vessel (262 m long), another container vessel $(319 \mathrm{~m})$, a roll-on rolloff vessel $(135 \mathrm{~m})$ and a tanker $(227 \mathrm{~m})$. Results are provided in terms of $\mathrm{KG}_{\max }$ curves, i.e. the maximum value of $\mathrm{KG}$ ensuring compliance with the considered criterion 
Fig. 9 Maximum roll angle versus speed, influence of exponent in energy method

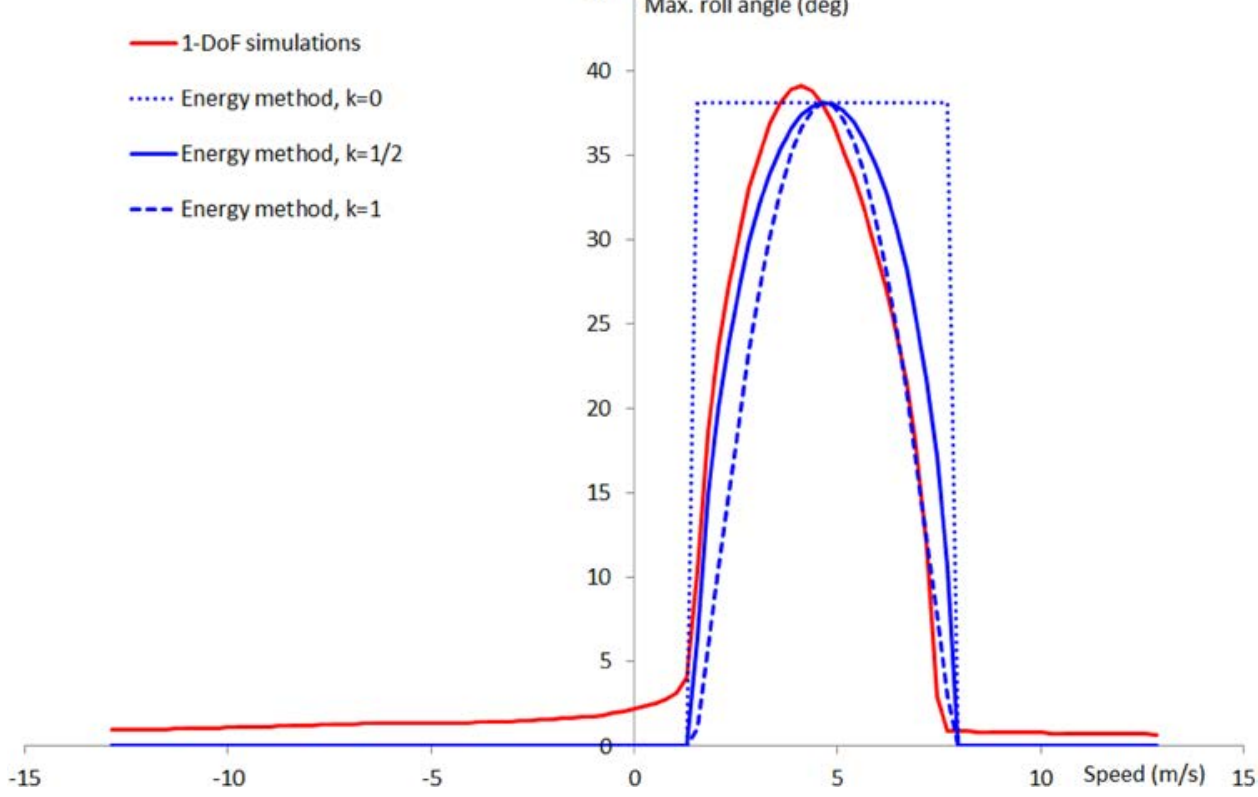

as a function of the displacement or the draught. Here, the second check $(\mathrm{C} 2)$ is seen as a separate criterion, although it is embedded in a unique level-2 criterion with the first check (C1). Results are given in Figs. 10, 11, 12 and $13 . \mathrm{KG}_{\max }$ curves obtained with the energy method are compared to those obtained by numerical 1-DoF time-domain simulations assuming a linear and non-linear GZ in waves. The non-linear GZ in waves is calculated as the GZ in calm water modulated by the GM in waves, as proposed in the explanatory notes. The method used to construct the associated $\mathrm{KG}_{\max }$ curves is detailed in [9] and the comparison of $\mathrm{KG}_{\max }$ curves obtained by 1-DoF time-domain simulations with a linear and nonlinear GZ has been presented at the latest ISSW Meeting held in Stockholm (Sweden) in 2016 [10].

Figure 10 shows the results for the $\mathrm{C} 11$ container vessel, which is well known to be vulnerable to parametric roll [6]. We observe a good accordance of the three methods. In particular, the curves provided by $1-\mathrm{DoF}$ simulations with a linear and non-linear GZ are close to each other because of the linearity of the GZ in calm water up to $30^{\circ}$ (see [10]).
Fig. $10 \mathrm{KG}_{\max }$ curves associated with the 2 nd check of the parametric roll level 2 criterion for the $\mathrm{C} 11$ container vessel

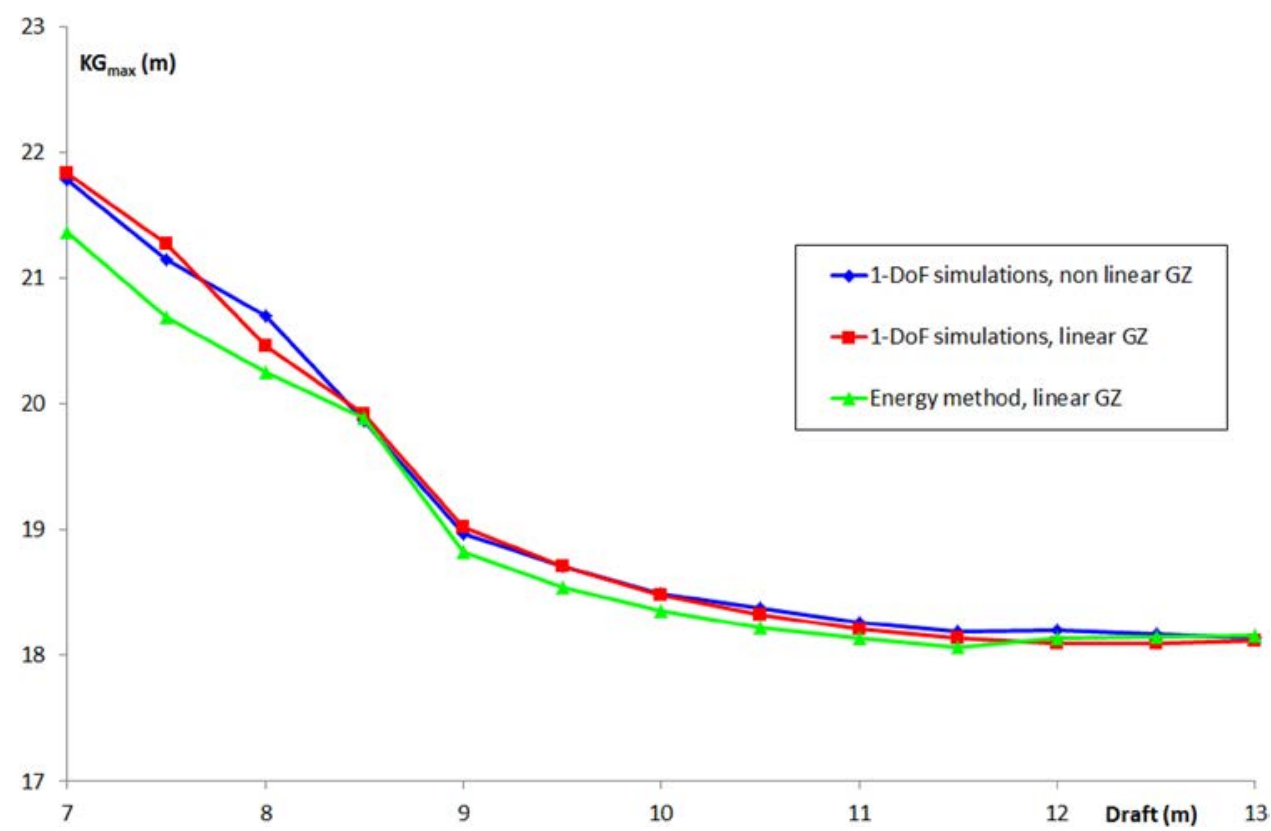


Fig. $11 \mathrm{KG}_{\max }$ curves associated with the 2 nd check of the parametric roll level 2 criterion for the $319 \mathrm{~m}$ container vessel
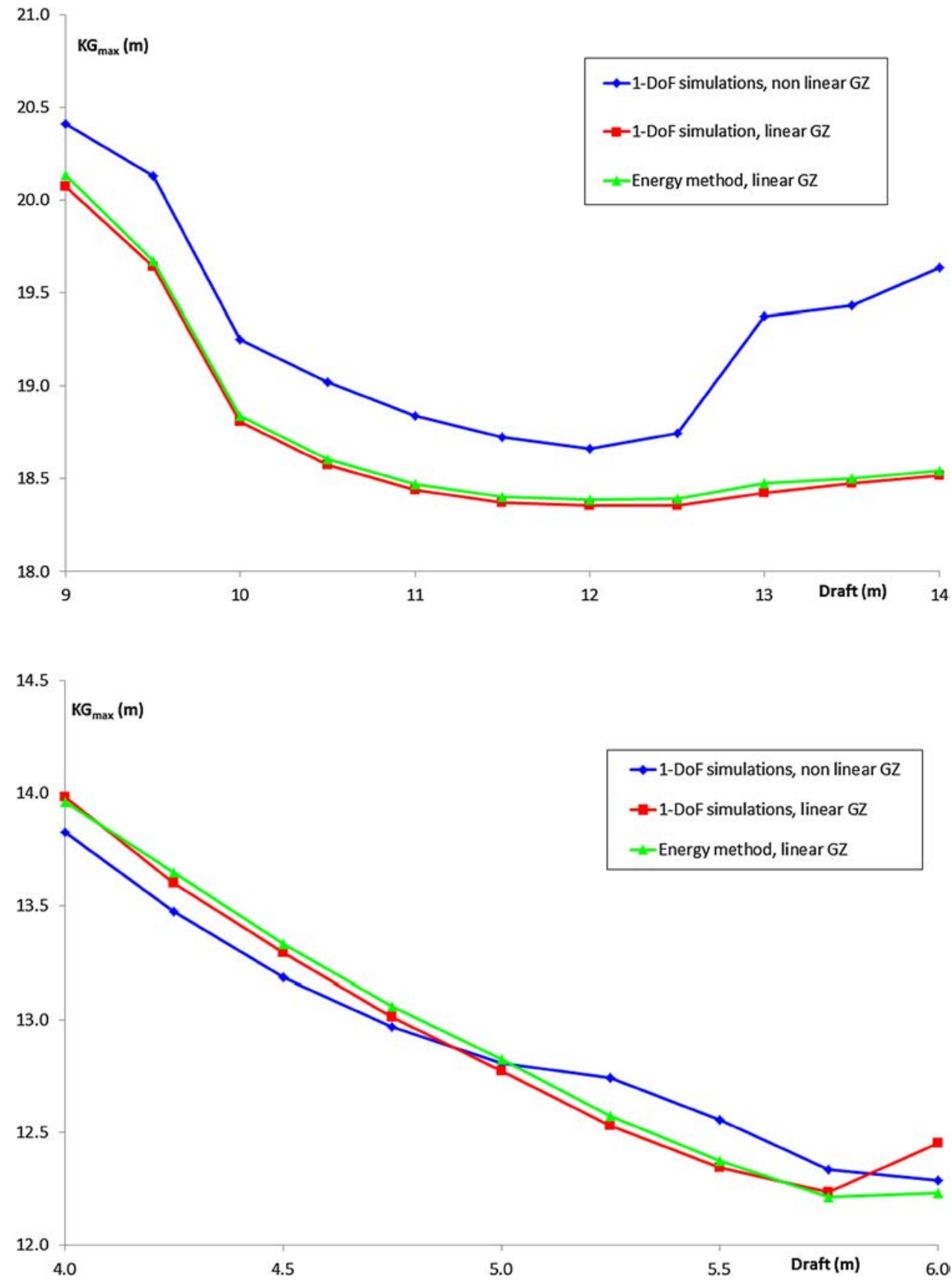

Fig. $12 \mathrm{KG}_{\max }$ curves associated with the 2 nd check of the parametric roll level 2 criterion for the Ro-Ro vessel
Figure 11 shows the results for the 319 m container vessel, assessed as vulnerable to parametric roll by the future criteria [9]. Both curves obtained with a linear GZ are in very good accordance. The curve obtained with a non-linear GZ significantly differs because of the high non-linearity of the GZ in calm water from $10^{\circ}$ (see [10]).

Figure 12 shows the results for the Ro-Ro vessel. Both curves obtained with a linear GZ are in very good accordance except for one point located beyond the full-load draught. The extension of computations at larger non-realistic draughts shows that the curves meet again. This local "jump" is characteristic of the $\mathrm{KG}_{\max }$ curves associated with the $\mathrm{C} 2$ criterion as explained in detail in [9].

Figure 13 shows the results for the tanker, assessed as non-vulnerable to parametric roll (see [9]), which is expected because of the wall-sided shape of her hull on 80 percent of her length. The accordance between both curves associated with a linear GZ is very high again. The gap between these curves and the one associated with a nonlinear GZ is explained in [10]. 
Fig. $13 \mathrm{KG}_{\max }$ curves associated with the 2 nd check of the parametric roll level 2 criterion for the tanker

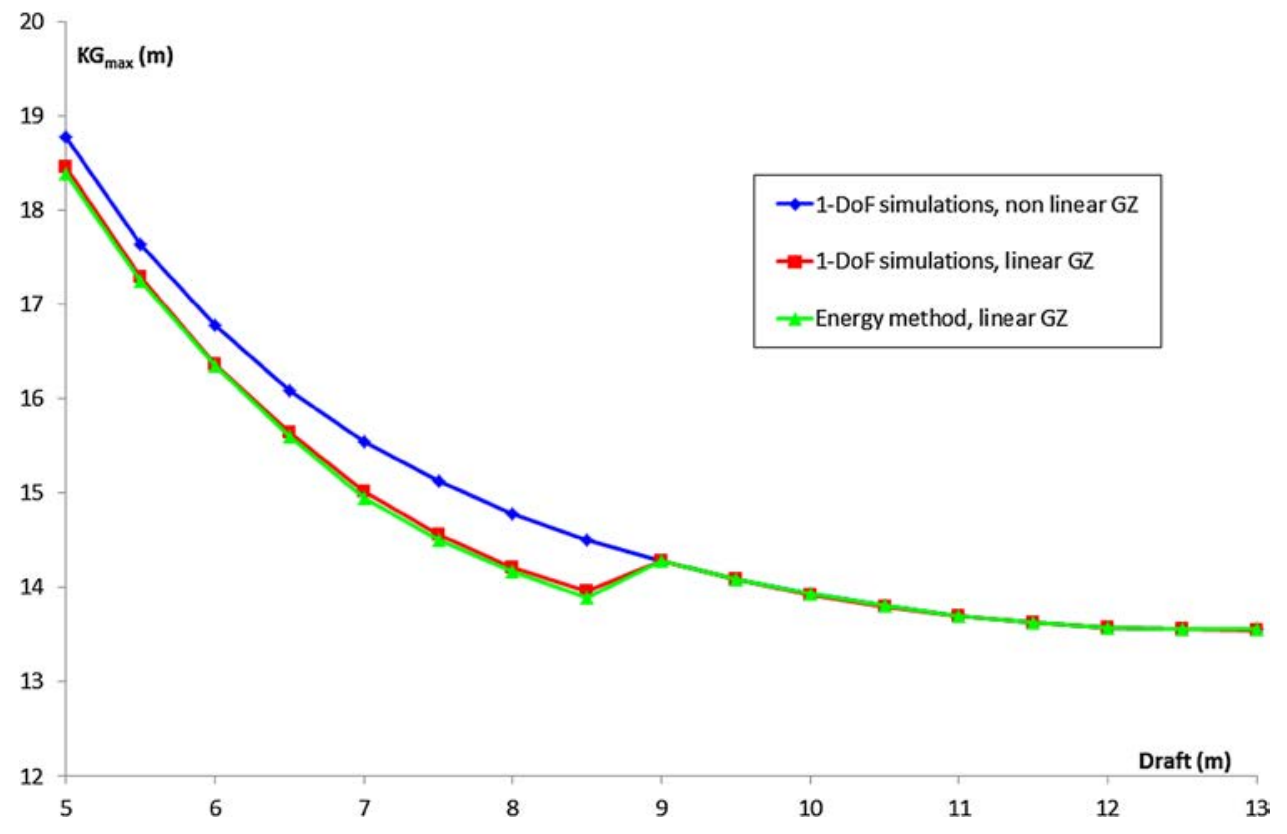

of this method in the second check of the level-two criterion of the future intact stability regulation is possible. This provides almost the same maximum allowed vertical centre of gravity $\left(\mathrm{KG}_{\max }\right)$ than the one-degree-of-freedom simulation with a linear GZ.

The linear GZ assumption up to $25^{\circ}$ is relevant for a large amount of vessels and conservative for most of other ships, such as the $319 \mathrm{~m}$ container vessel. The method proposed in this paper is easier to implement than those specified in the future regulation. Since the method is based on a physical analysis of the phenomenon and presents a complexity equivalent to that of the other level-two criteria, it is in full accordance with the three-level approach of the future regulation.

Although the mean value of the parametric exciting power is zero outside the first-mode lock-in field, parametric roll may occur with low amplitude in modes 2 and 3, where the ratios between the wave encounter frequency and ship's roll frequency are, respectively, equal to 1 and $2 / 3$. An improvement of the proposed method in these conditions would be interesting, even if the financial and safety risk is almost null or significantly reduced.

Acknowledgements The authors acknowledge the Members of CRNAV to Grant them authorization to use Fredyn software at the French Naval Academy within the scope of this project.

\section{References}

1. American Bureau of Shipping (2004) Guide for the assessment of parametric roll resonance in the design of container carriers. Sept. 2004, Updated June 2008, Houston, Texas 
2. Belenky V, Sevastianov NB (2007) Stability and safety of ships. SNAME, 2nd edn

3. Belenky V, Bassler C, Spyrou K (2011) Development of second generation intact stability criteria. US Navy, Naval Surface Warfare Center Carderock Division, NSWCCD-50-TR-2011/065

4. Bulian G (2006) Development of analytical nonlinear models for parametric roll and hydrostatic restoring variations in regular and irregular waves. PhD Thesis, Univeristy of Trieste, Italy

5. Carmel SM (2006) Study of parametric rolling event on a panamax container vessel. J Transp Res Board 1963:56-63

6. France WN, Levadou M, Treakle TW, Paulling JR, Michel RK, Moore C (2001) An investigation of head-sea parametric rolling and its influence on container lashing systems. SNAME Annual Meeting

7. Froude W (1861) On the rolling of ships. Trans Inst Naval Archit 2:180-227

8. Giordmaine JA, Miller RC (1965) Tunable coherent parametric oscillation in LiNb O 3 at optical frequencies. Phys Rev Lett 14(24):973

9. Grinnaert F, Billard J-Y, Laurens J-M (2016) $\mathrm{KG}_{\max }$ curves associated with 2 nd generation intact stability criteria for different types of ships. J Mar Sci Appl. doi:10.1007/s11804-016-1369-3

10. Grinnaert F, Billard J-Y, Laurens J-M (2016) Different computations of parametric roll Level 2 criterion. In: Proceedings of the 15th international ship stability workshop, 13-15 June 2016, Stockholm, Sweden

11. Hooft J P (1982) Advanced dynamics of marine structures. Wiley

12. Ikeda Y, Himeno Y, Tanaka N (1978) Components of roll damping of ship at forward speed. Department of Naval Architecture University of Osaka Prefecture, Report No 404
13. International Maritime Organization (2009) International code of intact stability, 2008. London

14. International Maritime Organization (2015) SDC 2/WP. 4, 2nd session. Development of Second Generation Intact Stability Criteria, Development of Amendments to Part B of the 2008 IS Code on Towing and Anchor Handling Operations

15. International Maritime Organization (2016) SDC 3/WP. 5, 3rd session. Finalization of second generation intact stability criteria, amendments to Part B of the 2008 IS code on towing, lifting and anchor handling operations

16. Kawahara Y, Maekawa K, Ikeda Y (2009) A simple prediction formula of roll damping of conventional cargo ships on the basis of Ikeda's method and its limitation. In: Proceedings of the 10th international conference on stability of ships and ocean vehicles, St Petersburg

17. Kerwin JE (1955) Notes on rolling in longitudinal waves. Int Ship-Build Prog 2(16):597-614

18. Maritime Research Institute Netherlands (2011) Fredyn User's manual, Version 10.3. May 2011

19. Mathieu E (1868) Mémoire sur le mouvement vibratoire d'une membrane de forme elliptique. Journal de Mathématiques Pures et Appliquées 13:137-203

20. Sadat-Hosseini H, Stern F, Olivieri A, Campana EF, Hashimoto H, Umeda N, Bulian G, Francescutto A (2010). Headwave parametric rolling of a surface combatant. Ocean Eng 37(10):859-878

21. Sanmartín Losada JR (1984) O Botafumeiro: parametric pumping in the middle age. Am J Phys 52:937-945

22. Umeda N, Hashimoto H, Vassalos D, Urano S, Okou K (2004) Nonlinear dynamics on parametric roll resonance with realistic numerical modelling. Int Shipbuild Prog 51(2/3):205-220. 